\title{
GPs' views on the practice of physician-assisted suicide and their role in proposed UK legalisation: a qualitative study
}

Tariq Hussain and Patrick White

\begin{abstract}
\section{Background}

A bill to legalise assisted dying in the UK has been proposed in Parliament's House of Lords three times since 2003. The House of Lords Select Committee concluded in 2005 that 'the few attempts to understand the basis of doctors' views have shown equivocal data varying over time'. Fresh research was recommended to gain a fuller understanding of health sector views.
\end{abstract}

Aim

To examine GPs' views of the practice of physicianassisted suicide as defined by the 2005/2006 House of Lords (Joffe) Bill and views of their role in the proposed legislation; and to explore the influences determining GPs' views on physician-assisted suicide.

Design of study

Qualitative interview study.

Setting

Primary care in South London, England.

Method

Semi-structured interviews with GPs were conducted by a lead interviewer and analysed in a search for themes, using the framework approach.

\section{Results}

Thirteen GPs were interviewed. GPs who had not personally witnessed terminal suffering that could justify assisted dying were against the legislation. Some GPs felt their personal religious views, which regarded assisted dying as morally wrong, could not be the basis of a generalisable medical ethic for others. GPs who had witnessed a person's suffering that, in their opinion, justified physician-assisted suicide were in favour of legislative change. Some GPs felt a specialist referral pathway to provide assisted dying would help to ensure proper standards were met.

\section{Conclusion}

GPs' views on physician-assisted suicide ranged from support to opposition, depending principally on their interpretation of their experience of patients' suffering at the end of life. The goal to lessen suffering of the terminally ill, and apprehensions about patients being harmed, were common to both groups. Respect for autonomy and the right of self-determination versus the need to protect vulnerable people from the potential for harm from social coercion were the dominant themes.

Keywords

assisted suicide; general practice; legislation; opinions.

\section{INTRODUCTION}

In 2005 the Assisted Dying for the Terminally III Bill was introduced in the UK to the House of Lords, the upper house of parliament, seeking legislative change to allow doctors to participate in assisted dying. ${ }^{1}$ This law would allow a competent terminally ill patient the right to request and (after a 14-day period of reflection) receive medication from a physician with the express purpose of ending life. It is probable under such legislation that in the NHS, GPs would have significant involvement in assisted dying as part of their remit to care for terminally ill patients. ${ }^{2}$

The bill was referred to the Assisted Dying for the Terminally III Select Committee, which published its reports in 2005.,.$^{1,3}$ On 12 May 2006, the bill was debated and an amendment to delay its introduction was carried by a margin of 148 to 100 votes.

Doctors' views of assisted suicide have been acknowledged previously as authoritative because of their direct experiences of end-of-life care compared to those of the lay public. ${ }^{3}$ However, recent British Medical Association (BMA) policy, ${ }^{4}$ and the Lords Select Committee Report, ${ }^{3}$ also noted the divided views of doctors on this subject. Most of the research in this area has been studied without qualitative preparation, exploring individual attitudes and the conceptualisation of those attitudes. ${ }^{5,6}$ Often

T Hussain, BSc, MSc, DCH, MRCGP, GP, Downs Way Medical Practice, Gravesend. P White, MRCP, FRCGP, GP and senior lecturer in general practice, Department of General Practice and Primary Care, King's College London School of Medicine, London.

Address for correspondence

Dr Tariq Hussain, Downs Way Medical Practice, Worcester Close, Istead Rise, Gravesend, Kent DA13 9LB.

E-mail: tariqhussain@nhs.net

Submitted: 10 January 2009; Editor's response: 18 March 2009; final acceptance: 7 July 2009.

(C)British Journal of General Practice 2009; 59: 844-849.

DOI: 10.3399/bjgp09X472908 
such research results in polls of opinion, with narrow margins of support or opposition and significant abstentions, which make a clear understanding of doctors' views difficult. ${ }^{7-10}$

The research described here was designed to examine GPs' views on physician-assisted suicide and how their views were formed. The overall aim of the research was to enable GPs' views to be taken into account in subsequent drafting of legislation.

Public opinion in the UK has moved in favour of assisted dying, driven by high-profile cases of terminally ill patients requesting the right to die in the manner of their choosing. ${ }^{11,12}$ British social attitude surveys conducted by the National Centre for Social Research showed in 1984, 1989, and 1994 an increasing majority in favour of doctors being allowed to end the life of a patient suffering from 'a painful incurable disease'. ${ }^{11}$ UK citizens have also been travelling abroad to seek assistance in dying. ${ }^{12}$ Four national or state legislatures have passed laws to permit assisted suicide and/or voluntary euthanasia: the US state of Oregon (1997), the Netherlands (2002), Belgium (2002), and Luxembourg (2009). At the annual general meeting of the BMA in 2005, a proposal that the BMA should lobby in favour of assisted dying was rejected by $58 \%$ to $42 \% .^{4}$ Previous studies have revealed polarised views among doctors themselves, affected by their religious beliefs, ethnicity, medical specialty, and concern about a slippery slope of legislative change, about undetected depression among those requesting physician-assisted suicide, and about practical issues regarding safeguards. ${ }^{13,14}$

\section{METHOD}

This research was a qualitative interview study of inner-London GPs. The interviewer stated no specific agenda regarding physician-assisted suicide legislation and no connection or affiliation to any organisation voicing opinions regarding physicianassisted suicide. The interview style was nonjudgemental and balanced, the achievement of which was reviewed by both authors in audio recordings. A purposive stratified sampling approach was used to include views from male and female GPs, ${ }^{6}$ with ranges of age and experience, different religious and cultural backgrounds, and including GPs with special interests in ethics, palliative care, and nursing home care.

\section{Recruitment}

Participants were GPs in NHS general practice in south London, identified through local general practices and through their affiliation with organisations such as local hospices, mission practices, local sector groups, and centres teaching medical ethics. They were approached via telephone

\section{How this fits in}

Physician-assisted suicide is a topical issue with passionate and genuinely

compassionate debate from those in favour and those against. However

legislative decisions have too often been based on personal sentiments as medical evidence-based research is limited to equivocal and ambiguous number studies. This research looks at the vital opinions of GPs in this debate and for the first time asks 'why questions'. In doing so, the conflicts and the common ground between ideologues is revealed and discussed.

and e-mail. GPs who declined to give consent and GPs who withdrew from the study were excluded. The semi-structured interview topic guide was devised after consulting published studies. ${ }^{13,14}$ Two pilot interviews were conducted. After each interview the interview guide was reviewed and amended where appropriate.

Participants were e-mailed a summary (written by the researcher) of the Assisted Dying for the Terminally III Bill, with quotes from the bill and a link to the transcript. ${ }^{1}$

Semi-structured interviews were conducted in GPs' surgeries or homes from December 2007 to April 2008. ${ }^{15,16}$ The interviews were recorded, transcribed verbatim, and analysed using the framework approach. ${ }^{17,18}$ Primary analysis was conducted by the lead researcher. Emergent themes were reviewed and checked by the second author. Written consent was obtained from each GP before their interview, and reconfirmed after the interview.

\section{RESULTS}

Thirteen GPs took part in the study. Three were female, four GPs described themselves as Christian, four as atheist, two as agnostic, one as Hindu, one as Muslim, and one as Jewish. The sample ranged in age from 30 to 56 years (median 51 years). Length of service in general practice ranged from 2 to 28 years (median 22 years). Three GPs had a special interest in medical ethics, three in terminal care, and 10 in providing care to nursing home residents. Quotes of doctors are referenced numerically.

\section{GPs' views on the practice of physician- assisted suicide}

Three core themes were identified and described.

The role of a doctor/specialist thanatology service. Some GPs were concerned that this was a nonmedical issue historically, and in discord with the first duty of a doctor as prescribed by the UK General Medical Council to: 'make the care of your patient your first concern':

'Why should doctors do this? It should be someone who is in the best position to make the 
right decision to assist patients with their wishes and it may be that doctors aren't the ones who want to do it.' (Dr 3)

However, other GPs noted how performing this kind of service could actually be viewed as integral to the role of a GP:

'If somebody did make that autonomous choice [for physician-assisted suicide], I wouldn't wish to disengage myself from it and actually it is probably the last service you can render to somebody in that situation and there is something rather cowardly, in the absence of a moral objection, [about] leaving it to somebody else.' (Dr 11)

'Thanatologist' was a term coined by one GP to mean expert in death, and a specialist service (not necessarily GP led) was mooted which might take on this role:

'Palliative care physicians if they were actually the agents of assisting dying might find that their reputation would change, the patients feeling it would be more powerful for their primary care physicians to be involved or even a specialist thanatologist.' ( $\mathrm{Dr} 11)$

Capacity and consent. Some GPs were concerned about the practical difficulties of separating appropriate sadness at the end of a possibly painful terminal illness from clinical depression. Others pointed out the conflicting influences on a patient and the difficult area of understanding someone's choices and then ensuring that choice is in their best interests:

'I think that erm it may be very difficult to decide if someone is depressed in the end-of-life situation. It is a very difficult grey area and [involves] distinguishing sadness and feelings of loss because you are terminally ill, which can be seen as natural feelings distinct from being mentally ill and depressed.' (Dr 13)

Concerns regarding 'patient autonomy'. Conflict between GPs was also shown in the area of patient autonomy, with some GPs feeling that autonomy was an absolute right that a patient either had or didn't have. Other GPs considered that autonomy should be relative and that limitless patient autonomy could do harm:

I feel that people do have a right to determine how their life goes as much as they can and that if they are in a position where they know their life is imminently to end and they do have capacity and they do have the wish to bring that forward, then they are within their rights to do that.' (Dr 6)

'Just because a patient wants something it doesn't mean it is the right thing for them.' ( $\operatorname{Dr} 10)$

Other areas reported at interview were the desirability of increasing recognition of the role of the family and the need for adequate training, local guidance, and audit/review of new processes.

\section{GPs' views of the legislation of physician-assisted suicide}

Three core themes were identified. All interviewees felt the legislation was logical, well thought through, and patient centred with a strong emphasis on patient autonomy. In contrast with the acknowledgement of the role of patient autonomy, a few GPs were concerned about the fundamental direction of assisting someone to die and the harm that it could bring if patients felt a degree of imagined or actual social coercion.

Fundamentally unacceptable.

'I think for physician-assisted suicide there is definitely a short-term gain for a small group of individuals and I have, I hope, a genuine sympathy for those individuals, but I really feel quite alarmed by the prospects of long-term "disbenefit" for a much broader group of individuals.' (Dr 1)

In a fundamental sense, yeah I deep down morally would object to assisted dying based on my religious beliefs and my cultural upbringing which have shaped me.' (Dr 3)

'Sometimes when people are elderly and frail they actually think they are doing their relatives a favour by going a bit early, and I feel it can be very difficult to unpick that.' (Dr 10)

\section{Safeguards adequate?}

'I think that if it does become established and relatively common practice then potentially safeguards will slip.' (Dr 10)

'You only have to look at what happened in Nazi Germany in their euthanasia programme to see how easy it is for people to get swept into these things.' (Dr 5)

'If people are saying that it is a slippery slope into 
doctors knocking off patients, then that is clearly ridiculous. You don't have to have a slippery slope and you know if the bill is promulgated well enough then it would guard against that situation occurring.' (Dr 8)

Some GPs noted positively how the legislation included appropriate boundaries and the explicit definition of an autonomous choice. However, GPs were concerned about safeguards slipping, particularly for patients with mental health problems. Other GPs were less concerned about specific wording but more concerned about any safeguards being adequate.

\section{Role of social need}

GPs also disagreed as to whether there was a need for physician-assisted suicide:

'In 24 years in general practice I have not seen a situation where although people may have voiced that concern or desire [regarding physicianassisted suicide] that wasn't something that couldn't be overcome.' (Dr 4)

'I would argue that this never needs to happen $95 \%$ of the time but this bill will be there for the other small percentage.' (Dr 5)

'The very fact that people from the UK are travelling to other countries to access this service [physician-assisted suicide] demonstrates an unmet need in this country.' (Dr 8)

Some GPs would have favoured changes in the legislation for repeated assessments of patients' mental health and capacity over time, to pick up on depression or social pressures.

\section{Influences on GPs with respect to physician-assisted suicide}

Themes were categorised into three categories of experience, powerful others, or societal views.

Experience. Some GPs had not personally seen any need for physician-assisted suicide and felt goodquality palliative care could assuage the desire to prematurely end life. Other GPs had experiences that shaped how they thought about assisted dying:

'Some of my grandparents died of rather distressing chronic respiratory illnesses and watching them die in the best way, actually they had, I believe they had, the best care that was available at the time but I still don't believe it was good enough for them.' (Dr 8)
Powerful others.

'Professionally I have been influenced by my stints in elderly care in hospital; personally my parents, particularly my mum has influenced my moral framework.' (Dr 6)

'It is a religious conviction that life here has a meaning outside just our earthly existence. There is something sacred about the essential humanity of all people and that needs to be fundamentally accepted and that comes from upbringing.' ( $\operatorname{Dr} 4)$

However, Dr 4 went on to say:

'I suppose it is for those kind of more objective reasons [harm to individuals] that I would be worried irrespective of you know the religious beliefs side of things.'

'Yes I think for me it [religion] is a starting point, but I have never been very persuaded that they form an adequate basis for a generalisable medical ethic. When push comes to shove I don't agree with simple divine command morality. I don't think you can uncouple potential for harm from the potential desirability of assisted suicide for a very small group of people. I just don't see a way of uncoupling those two issues. If there genuinely was I think I would have a different view of it.' ( $\operatorname{Dr} 1)$

Some GPs recognised how personal and professional experience and religious teaching influenced them. But it was not their religious orthodoxy that made them oppose physicianassisted suicide; instead, it was the concern regarding doing harm. Some acknowledged that if this could be resolved then their position might change. Others felt seeing patients suffer was the strongest experience that seemed to have the power to change the way they thought.

Societal views. Another important area noted by participants was recognising the power of the democratic views of a secular ageing population living with chronic disease and increasing medicalisation, and respecting those who choose a path that, through increasing technological advancements, doctors have tried to forestall:

'We have to be responsive to the views of our patients collectively, and actually we live in a democratic society and I think if their Lordships [members of the House of Lords, upper house of 
the UK Parliament] had any reference point in what the public thinks then they would be more sympathetic.' (Dr 11)

\section{DISCUSSION}

\section{Summary of main findings}

GPs' views conflicted in several areas. Some GPs considered that physician-assisted suicide was fundamentally wrong, and that no safeguards would be strong enough to prevent vulnerable people from being harmed. However, some GPs considered that there were adequate safeguards and patient autonomy should be an absolute right. These GPs felt competent patients had the right of selfdetermination and to choose their own manner of death. Many of the GPs who saw patients with (in their opinion) unrelieved suffering, viewed physicianassisted suicide favourably and saw a need for it. Other GPs felt that adequate palliative care facilities obviated the need for assisted dying. GPs felt that the Assisted Dying for the Terminally III Bill was comprehensive.

Some GPs felt that assisted suicide was not part of the traditional role of the doctor as a healer. In practice, GPs felt there would be difficulties balancing patient autonomy with concerns from families of those with terminal illnesses, with complications regarding obtaining consent, and concerns ensuring the mental capacity of these patients.

The views of GPs regarding physician-assisted suicide were shown here to stem from a triad of experiential factors, societal factors, and discussions with respected others. GPs did not feel a specific religious principle as sufficient basis for a generalisable medical ethic for the treatment of others.

\section{Strengths and limitations of the study}

Strengths of this study include the use of a qualitative method to explore a multifaceted topic, in which GPs had varied and conflicting views. The demographic data in this study illustrate that the group of GPs interviewed contained a range of characteristics identified by previous research and targeted by the researcher as particularly relevant to physician-assisted suicide. ${ }^{8,9}$ A significant weakness is the small number of subjects interviewed, which may have prevented thematic saturation from being achieved. A second weakness is that the doctors sampled had more than the average experience of terminal care. However, the quality of data may be higher from those who were likely to have given the matter some thought. Not all these doctors shared a single viewpoint, as shown by the divergent views expressed. The study sample may not have represented the full range of GPs' views. Therefore, the study may lack generalisability to other doctors in other parts of the country or other groups of GPs.

However, the views are striking and important and there is an interesting balance in the views that is compelling. Other limitations of the study include data collected using only one method of interview, and triangulation from other methods of data collection such as group discussion may increase the validity of the results. ${ }^{5}$

\section{Comparison with existing literature}

This study responds to the request from the House of Lords Select Committee in 2006 for more deliberative research of doctor's views about physician-assisted suicide. ${ }^{3}$ This is also the first research to provide qualitative data about how UK doctors feel about the Assisted Dying Bill. This places the debate in real-time context and rather than personal views gives evidence-based opinion to the director of public prosecutions' recent consultation regarding clarification of the law regarding assisting suicide, as well as inform any possible future debate on legislation regarding physician-assisted suicide. ${ }^{19}$

GPs have been shown to differ in their views regarding physician-assisted suicide. ${ }^{7}$ Evidence presented for the first time here shows that, based on their experience, GPs either think there is a need for a specialist physician-assisted suicide service legalised by reasonable laws with adequate safeguards, or they think safeguards are not strong enough to prevent harm coming to vulnerable individuals and this outweighs any perceived need. This is in contrast to research by Curry et al who thought the role of a physician's personal values were central to the discussion about legislation of physician-assisted suicide, ${ }^{14}$ and the work of Mackinnon et al, who felt the religiosity of doctors affected their care of the terminally ill. ${ }^{20}$ Familiarity with the care of the terminally ill affects how doctors consider assisted dying. This is shown here and in other studies. ${ }^{21}$ However, this study also found significant cross-over of opinion among all to improve end-of-life care for those suffering. Bernheim and colleagues have shown, in Belgium, how, rather than polarising opinion by focusing attention either on improving palliative care or legalising assisted dying, both positions have common goals that could be shared and amalgamated in the development of a unified service to improve the quality of end-of-life care. ${ }^{22}$

\section{Implications for future research}

The views of GPs are opposing, with some who have concerns that seem impossible to assuage, 
feeling the law must remain unchanged, and others who favour a rewriting of the legislation. Opinions most sharply contrasted in the area of patient autonomy: some GPs felt that autonomy should be absolute; others felt that autonomy had a more contingent quality and that social coercion could lead to harm if vulnerable people felt pressured to prematurely end their lives.

Despite areas of conflict, there was common ground. All GPs wanted to reduce the suffering of patients, respect the rights of the individual, preserve patient autonomy, and protect the vulnerable from coercion. Future research could look into a possible consensus focusing on these areas. Further work needs to have a large enough sample size to be able to extrapolate the views to all GPs and help reach a democratic agreement. This could be done by a quantitative survey that would ensure true representation of views.

It is not primarily from a religious or cultural deontological position that doctors feel physicianassisted suicide is right or wrong for others, but more from the view of consequentialism that legislative change has positive and negative implications. The goal to lessen suffering of the terminally ill and apprehensions about patients being harmed by the influence of others are common to both groups. By engaging in debate based on good-quality evidence rather than personal opinion or moral ideology, it might be possible to assuage these concerns to reach a consensus. If legislation is pursued, there will be a better understanding of the possible role of GPs and the conflicts they will face in supporting and assisting their patients.

\section{Funding body}

This study was conducted with no external funding. Research support was provided by the Department of General Practice and Primary Care, King's College London. Financial incentives were not provided to participants

\section{Ethics committee}

Ethical approval was given by the King's College Hospital Research Ethics Committee. Research governance approval was given by The Greenwich, Lambeth, Lewisham, and Southwark Research and Development Centre: REC reference number: 07/H0808/142; R\&D reference: RDLSL 380

\section{Competing interests}

The authors have stated there are none; the views expressed in this paper have not been influenced by any supporting or outside source

\section{Acknowledgements}

We would like to thank all the GPs who participated, for their time and thoughtfulness. Thanks to Professor Roger Jones and Dr Kalwant Sidhu for comments on the design and the manuscript, and to Beryl Stevens for administrative support. Thanks also to our families and to the MSc 20 cohort for their support and care.

\section{Discuss this article}

Contribute and read comments about this article on the Discussion Forum: http://www.rcgp.org.uk/bjgp-discuss

\section{REFERENCES}

1. House of Lords. Assisted Dying for the Terminally Ill Bill [HL]. London: Stationery Office, 2005.

http://www.publications.parliament.uk/pa/ld200506/ldbills/036/0603 6.i.html (accessed 25 Sep 2009).

2. Department of Health. Delivering investment in general practice. Implementing the new GMS contract.

http://www.dh.gov.uk/prod_consum_dh/groups/dh_digitalassets/@d h/@en/documents/digitalasset/dh_4070231.pdf (accessed 5 Oct 2009).

3. House of Lords Select Committee on the Assisted Dying for the Terminally Ill Bill. Assisted Dying for the Terminally Ill Bill [HL] Report. HL 86-I, 86-II, 86-III. London: Stationery Office, 2005. www.publications.parliament.uk/pa/ld/ldasdy.htm (accessed 25 Sep 2009).

4. Sommerville A. Changes in BMA policy on assisted dying. BMJ 2005; 331(7518): 686-688.

5. Mays N, Pope C. Qualitative research in health care. 2nd edn. London: British Medical Journal Books, 1999.

6. Murphy E, Mattson B. Qualitative research and family practice: a marriage made in heaven? In: Carter Y, Shaw S, Thomas C (eds). An introduction to qualitative methods for health professionals. London: Royal College of General Practitioners, 1999: 29-34.

7. Pasterfield D, Wilkinson C, Finlay IG, et al. GPs' views on changing the law on physician-assisted suicide and euthanasia, and willingness to prescribe or inject lethal drugs: a survey from Wales. Br J Gen Pract 2006; 56(527): 450-452.

8. Dickinson GE, Lancaster CJ, Clark D, et al. UK physicians' attitudes toward active voluntary euthanasia and physician-assisted suicide. Death Stud 2002; 26(6): 479-490.

9. Craig A, Cronin B, Eward W, et al. Attitudes toward physicianassisted suicide among physicians in Vermont. J Med Ethics 2007 33(7): 400-403.

10. Curry L, Gruman C, Blank K, Schwartz HI. Physician-assisted suicide in Connecticut: physicians' attitudes and experiences. Conn Med 2000; 64(7): 403-412.

11. National Centre for Social Research. British social attitude surveys. www.natcen.ac.uk/index.html (accessed 25 Sep 2009).

12. Dyer C. Swiss parliament may try to ban 'suicide tourism'. BMJ 2003; 326(7383): 242.

13. Dobscha SK, Heintz RT, Press N, Ganzini L. Oregon physicians' responses to requests for assisted suicide: a qualitative study. J Palliat Med 2004; 7(3): 451-461.

14. Curry L, Schwartz HI, Gruman C, Blank K. Physicians' voices on physician-assisted suicide: looking beyond the numbers. Ethics Behav 2000; 10(4): 337-361.

15. Rubin HJ, Rubin IS. Interviews as guided conversations. In: Rubin HJ, Rubin IS, eds. Qualitative interviewing: the art of hearing data. London: Sage, 1995; 122-144.

16. Britten N. Qualitative interviews in medical research. BMJ 1995; 311(6999): 251-253.

17. Pope C, Ziebland S, Mays N. Qualitative research in health care. Analysing qualitative data. BMJ 2000; 320(7227): 114-116.

18. Ritchie J, Spencer L. Qualitative data analysis for applied policy research. In: Bryman A, Burgess RG (eds). Analysing qualitative data. London: Routledge, 1996; 173-193.

19. Palmer A. Why we must not make the 'right to die' legal. Daily Telegraph 2008; 8 June:

http://www.telegraph.co.uk/comment/personal-view/3559260/Whywe-must-not-make-the-right-to-die-legal.html (accessed $25 \mathrm{Sep}$ 2009).

20. Mackinnon NJ, Molson JD, May JD. Physician interventions in the dying process: a causal model of physician attitudes and the subjective likelihood of engaging in active euthanasia, physicianassisted suicide, and withholding treatment to terminally ill patients. Electronic J Sociol 2003. http://www.sociology.org/content/vol7.1/mackinnon_etal.html (accessed 25 Sep 2009).

21. Marini MC, Neuenschwander H, Stiefel F. Attitudes toward euthanasia and physician-assisted suicide: a survey among medical students, oncology clinicians, and palliative care specialists. Palliat Support Care 2006; 4(3): 251-255.

22. Bernheim JL, Deschepper R, Distelmans W, et al. Development of palliative care and legalisation of euthanasia: antagonism or synergy? BMJ 2008; 336(7649): 864-867. 